\title{
Biomechanical and Physiological Conditions Influence Erythrocytes - Erythrocyte Adhesion. An in vitro Study
}

\author{
Mohamed A. Elblbesy ${ }^{1,2}$ \\ ${ }^{1}$ Department of Medical Biophysics, Medical Research Institute, Alexandria University, Egypt \\ ${ }^{2}$ Department of Medical Laboratory Technology, Faculty of Applied Medical Science, University of Tabuk, Saudi \\ Arabia \\ Correspondence: Mohamed A. Elblbesy, Department of Medical Biophysics, Medical Research Institute, \\ Alexandria University, Egypt. E-mail: mimizizo@yahoo.com
}

Received: May 17, 2017

Accepted: June 8, 2017

Online Published: July 24, 2017

doi:10.5539/apr.v9n4p23

URL: https://doi.org/10.5539/apr.v9n4p23

\begin{abstract}
Erythrocyte - erythrocyte adhesion (EEA) is of the large interest since it will effect directly on its function and interaction with other organs. Also, erythrocytes adhesion may arise erythrocytes aggregation which has a significant effect on the hemodynamic mechanism. The present study is aimed at examining the effect of erythrocytes mechanical properties on their adhesion. In addition, the impact of the physiological conditions around erythrocytes on their adhesion will be evaluated. A simple flow compartment technique built on inverted microscope was used to calculate adhesion number (AN) of erythrocytes which reflects the ability of erythrocytes to adhere to each other. AN was correlated strongly to shear rate and erythrocyte deformation index. Shape parameters of erythrocytes (Radius and volume) were found to play a major role in EEA. The concentration of the main plasma proteins (fibrinogen and albumin) were determined to have a significant effect on EEA. The results obtained in this study give the attention that other factors rather than particle diameter and work of adhesion may effect on erythrocytes adhesion.
\end{abstract}

Keywords: Erythrocytes, Adhesion, Shear Rate, Deformation, Shape, Plasma proteins

\section{Introduction}

Adhesion could be defined as the attraction between two solid bodies produced by short distance intermolecular forces. Adhesion takes place between bodies with common contact surfaces (Zhou, 2003). A considerable number of researchers have been focused on the problems of adhesion (Corn, 1961; Kordecki \& Orr Jr, 1960). Determination of adhesion force is crucial for many biomedical applications (Leckband \& Israelachvili, 2001).

Erythrocytes are the major cell components of blood. They are $8 \mu \mathrm{m}$ in diameter with biconcave shape and 120 days lifespan (Pasini et al., 2006). The Erythrocytes membrane content is similar to most of the animal membranes, and it is composed of water, proteins, lipids, and carbohydrates (D. Zhang, Kiyatkin, Bolin, \& Low, 2000). It was believed that erythrocyte membrane consisted of the punch of lipids and one single protein. A few decades ago, it was revealed that red cell membrane ghosts had more than just one single protein. Recently, Pasini et al. had already made the identification of at least 340 different red cell membrane proteins (Pasini et al., 2006).

Erythrocytes are considered as non-adhesive cells. The expression of a vast number of adhesion molecules was found in erythrocytes (Brittain, Han, Ataga, Orringer, \& Parise, 2004; Brown \& Frazier; Dahl, Westhoff, \& Discher, 2003; Garratty, Telen, \& Petz, 2002; Goel \& Diamond, 2002; Hermand et al., 2003). Adhesion molecules play a crucial role in cell- cell and cell-tissue interactions (Hermand et al., 2003; Ihanus, Uotila, Toivanen, Varis, \& Gahmberg, 2007; Telen). Normal erythrocytes do not adhere to circulating cells and vessel walls under normal circumstances, suggesting that erythrocyte adhesion molecules could be inaccessible to their ligands. Adhesion of erythrocytes increases during particular homeostatic and pathological conditions i.e. clot formation and sickle cell disease (Goel \& Diamond, 2002; Hermand et al., 2003; Wautier \& Wautier, 2004; Zen, Cottman, Truskey, Fraser, \& Telen, 1999). Erythrocytes have at least the potential capability of adhering to some ligands including thrombospondin, fibronectin, laminin, hyaluronan, and thus to other cellular types such as endothelial cells and leukocytes (Wautier \& Wautier, 2004; Zen et al., 1999). Erythrocytes float freely around the body without adhering 
strongly to other structures under normal conditions. Erythrocytes adhesion may be described through weak van der Waals adhesive forces alone which is much weaker than chemical bonds (Kendall, Liang, \& Stainton, 1998).

There are many techniques to measure the adhesive forces, including Atomic force microscopy (AFM), centrifugal method, and electric field detachment method (Salazar-Banda, Felicetti, Gonçalves, Coury, \& Aguiar, 2007; Shukla \& Henthorn, 2009; Zafar, Hare, Hassanpour, \& Ghadiri, 2014). For a particle with irregular shape, the adhesive force is hard to be measured (LaMarche, Muzzio, Shinbrot, \& Glasser, 2010; Packham, 2003).

In the present study erythrocytes-erythrocyte adhesion (EEA) has been evaluated under different shear rates microscopically. There are some studies of erythrocytes aggregation were based on microscopic techniques (Baskurt, Meiselman, \& Kayar, 1998; Berliner et al., 2004; Shiga, Imaizumi, Harada, \& Sekiya, 1983). The main difference between them and the present work is that the present work represents adhesion number (AN) to evaluate the force of adhesion under the different shear rates. By which more in deep analysis of erythrocytes aggregation could be gained, and the phenomena of aggregation could be studied on the cellular level. One of the main aims of the present study is to evaluate the effect of the deformation of erythrocytes on their aggregation ability. The correlations between AN and physiological condition such as erythrocytes shape parameters and plasma proteins has been studied.

\section{Materials and Methods}

\subsection{Samples Collection and Preparation}

Thirty blood samples were collected from healthy volunteers with the same age and gender. All blood samples were collected after overnight fasting in a quiet environment at normal ambient temperature. Blood was withdrawn after a $10 \mathrm{~min}$ resting period and in a seated position. Five $\mathrm{ml}$ of blood was collected on EDTA as an anticoagulant and divided into two parts as the following:

- $\quad 2.5 \mathrm{ml}$ was used to determine the mean cell volume (MCV), red blood cell distribution width (RDW), and hemoglobin (HGB)

- $\quad 2.5 \mathrm{ml}$ was centrifuged, and erythrocytes were separated from plasma. The sequence of erythrocytes suspensions in autologous plasma of concentrations $0.0002,0.0004,0.0006,0.0008,0.001 \mathrm{v} / \mathrm{v}$ were prepared and were utilized in the determination of adhesion number (AN).

Two $\mathrm{ml}$ from the same volunteers was collocated on $3.2 \%$ sodium citrate to determine fibrinogen level in plasma. Other two $\mathrm{ml}$ was collected on serum gel to determine albumin level in serum.

\subsection{Erythrocytes Adhesion Number under different Shear Rates}

To study erythrocytes adhesion under different shear rates an instrument was built up in my lab called flow compartment. This instrument composed of a cone of glass over a flat glass slide. The cone and slide made an angle of $3^{\circ}$ with horizontal. This small angle helped in avoiding of depletion effect of the walls. The cone was connected to stepper motor through a rubber belt. The erythrocytes suspension was introduced in the gap between the cone and slide. Both the cone and slide were built in a plastic holder and were fixed on the stage of the inverted microscope. This instrument allowed to exposed erythrocytes to shear rates range between $5 \mathrm{~s}^{-1}$ to $200 \mathrm{~s}^{-1}$, and this was done by changing the angular velocity of the rotation of the cone to give the desirable values of shear rate. An eyepiece camera was attached to the inverted microscope, by which images of the erythrocytes under different shear rates were taken. Hence, I had the opportunity for an in-depth analysis of the dynamics of EEA under steady shear conditions.

\subsection{Calculation of Adhesion Number}

Doublets erythrocytes $\left(\mathrm{N}_{2}\right)$ and singlet erythrocytes $\left(\mathrm{N}_{1}\right)$ are related to volume fraction $(\phi)$ by the following equation:

$$
N N_{2} / N_{1}^{2}=4 \phi\left(\lambda^{3}-1\right) \exp (\varepsilon / k T) \approx N_{2} / N_{1}
$$

From this argument, the scattering plot of $N_{2} / N_{1}$ versus volume fraction $(\phi)$ give a straight line passing through the origin. The slope of the line is a measure of the adhesion and is called adhesion number (AN) (Liang \& Kendall, 1998).

$50 \mu \mathrm{l}$ of erythrocytes suspension was placed in flow compartment. Images of erythrocytes under different shear rates were transferred to PC by eyepiece camera. Images were transferred directly to PC and saved in appropriate format with high resolution. All images were converted into gray scale. Imaging processing software ImageJ (imagej.nih.gov/ij/download/) was used in the analysis of erythrocytes images. It was able to count multiplets $\left(\mathrm{N}_{2}\right)$ and singlet $\left(\mathrm{N}_{1}\right)$ erythrocytes by using counting particles and particles area tools which are available in ImageJ. 
The previous procedure was followed for each erythrocytes suspension under different steady conditions and different shear rates.

\subsection{Calculation of Deformation Index}

The filtration method was used to evaluate the erythrocytes deformability which was described in details elsewhere (Reid, Barnes, Lock, Dormandy, \& Dormandy, 1976; Shevkoplyas, Yoshida, Gifford, \& Bitensky, 2006). Briefly, five $\mu \mathrm{m}$ track-etched polycarbonate filters (Nuclepore ${ }^{\mathrm{TM}}$, Whatman, GE Healthcare Biosciences, Piscataway, NJ, USA) were pre-wetted with $40 \%$ ethyl alcohol. $100 \mu \mathrm{l}$ of erythrocytes suspended in autologous plasma was allowed to filtrate freely through the filter under the action of gravity. The Hct was adjusted at $10 \% .100 \mu$ of autologous plasma was allowed to filtrate freely through the filter after the same previous treatment. The deformation index (DI) was calculated as the following:

$$
D I=\frac{\text { Filteration time of erythrocytes suspention }}{\text { Filtration time of plasma }}
$$

\subsection{Statically Analysis}

The adhesion number for each sample was calculated ten times, and the mean $\pm \mathrm{SD}$ was obtained. The relationships between adhesion number and other parameters were examined with linear regression and correlation coefficient $\left(\mathrm{R}^{2}\right)$ was calculated. $R^{2} \geq 0.6$ was considered as strong correlation. $0.5 \leq R^{2} \leq 0.6$ was considered as moderate correlation. $R^{2} \leq 0.5$ was considered as weak correlation.

\section{Results and Discussion}

Erythrocytes adhesion could be measured by observing the number of doublets at equilibrium in a dilute suspension (Attenborough \& Kendall, 2000; Liang \& Kendall, 1998). K. kendall et al. in their work to compare adhesion number of human erythrocytes to the adhesion number of other mammalian proven the linearity of the relationship between $N_{2} / N_{1}$ versus volume fraction $(\phi)$ for human erythrocytes (Attenborough \& Kendall, 2000; Kendall \& Stainton, 2001; Liang \& Kendall, 1998). Linear relationship for $N_{2} / N_{1}$ as a function of, $\phi$, was obtained as shown in Figure 1. For erythrocytes suspended in plasma, the mean value of AN was $491 \pm 12$. Attenborough, F.R et al, calculated AN for erythrocytes suspended in PBS and it was lower than the value obtained in the present study (Attenborough \& Kendall, 2000). This can be explained as the plasma enhances the adhesion of the EEA. Blood has a non-Newtonian behavior. One of the major factor exhibit non Newtonian behavior of blood is erythrocytes aggregation. At low shear rates blood viscosity increases due to the formation of erythrocytes aggregation which starting as rouleaux and may be formed network shape under certain pathological conditions. At High shear rates blood, becomes less viscose due to lower a chance of erythrocytes to adhere with each other (Dintenfas, 1971; Schmid-Schönbein, Gallasch, Gosen, Volger, \& Klose, 1976). Cell-cell interaction under low shear rates is mediated by hydrodynamic force (Shiga et al., 1983). E. E Kaliviotis and M Yianneskis, showed that the aggregation index calculated microscopically was pointedly increased at low shear rate between 3 and $10 \mathrm{~s}^{-1}$. The aggregation index at high shear rates was reduced to the half of its value at low shear rates and value fluctuations was observed (Kaliviotis \& Yianneskis, 2007). The high viscosity value at low shear rates is aroused from the aggregation formation result in shear resistance. Johan Janzen et al indicated that at shear rates between 0.25 and $3 \mathrm{~s}^{-1}$ there was an increase in microscopic aggregation grade (Janzen, Elliott, Carter, \& Brooks, 2000). Figure.2. showed the effect of shear rates on EEA. At $50 \mathrm{~s}^{-1}$ the EEA obviously decreased due to the shear force which is greater than the value of the adhesion force. The hydrodynamic forces at high shear rates prevent EEA until equilibrium reaches at $90 \mathrm{~s}^{-1}$. Erythrocytes at high shear rates showed round and random motion in different direction. As observed in Figure 2. AN became approximately constant at $90 \mathrm{~s}^{-1}$.

An Adhesive surface energy and the elastic stored energy of erythrocytes results from deformation of the erythrocytes. The membrane elasticity is responsible for the elastic strain energy of the erythrocytes. Bending of the erythrocyte surface and shear lead to membrane elasticity. Both the aggregation and disaggregation process of the erythrocytes depends on the adhesive energy and elastic energy of deformation (Ernst, Pietsch, Matrai, \& Eisenberg, 1986). It was verified that the deformability of erythrocytes plays a major role in their main function. A slight decrease in erythrocytes deformability causes a significant increase in blood viscosity (Reid et al., 1976; Shevkoplyas et al., 2006). Figure 3. Shows strong correlation between AN and DI $\left(\mathrm{R}^{2}>0.6\right)$. From Figure 3. It can be concluded that when the erythrocytes membrane becomes less elastic, it loses its ability to adhere to other erythrocytes even to surfaces. This can be explained as the erythrocytes become stiffer reducing in adhesive force takes place 
It was concluded that the adhesion force should be proportional to particle diameter, and work of adhesion (Kendall $\&$ Stainton, 2001). It was maintained that the adhesion of micro size particles such as bacteria and blood cells depend on the roughness. It is presumed that roughness curvature rises in proportional to sphere diameter (Kendall \& Stainton, 2001). Shinde Patil, V. R., et al. suggested that attachment, rolling, and firm adhesion is functions of particle diameter and provides experimental proof for theoretical models that indicate a role for cell diameter in adhesion (Shinde Patil, Campbell, Yun, Slack, \& Goetz, 2001). JKR assumption stated that the adhesion of particle with the radius might be defined as the negative of the pull-off force F, and related to the surface energy $\gamma$ as the following:

$$
F=-\frac{3}{2} \pi \gamma R
$$

This formula assumes that the exciting of a strictly flat region of contact between the particles and that the particles experience an infinitely short-ranged interaction in this region and do not interact outside of it (Baskurt et al., 1998; Berliner et al., 2004; Shiga et al., 1983). Compatible with the previous studies, Figure 4. shows strong correlation $\left(R^{2}>0.6\right)$ between AN and RDW in Plasma. Linear increase in AN as RDW increase was observed in the present study. This can be explained as the a $\mu \mathrm{m}$ particles dominated by adhesion forces due to dwarf in their diameter. Also the roughness of the surface of $\mu \mathrm{m}$ particles play a key role in adhesion and proportion directly with the particle diameter.

Nancy J. et al. mentioned that the adhesion of erythrocytes could be influenced by erythrocytes volume (Wandersee et al., 2005). Felicetti, M. A., et al. illustrated in their study that the adhesion force is a function of the mean particle diameter of powdery materials and they noted the increasing of adhesion force as particle size increased(Felicetti, Piantino, Coury, \& Aguiar, 2008). Figure 5. depicts the direct relation between AN and MCV. The correlations of this coordinate was moderate $\left(0.5 \leq R^{2} \leq 0.6\right)$. The particle volume and adhesion inter relationship may be raised from the increasing of the roughness of the particles surface as particle's volume increase.

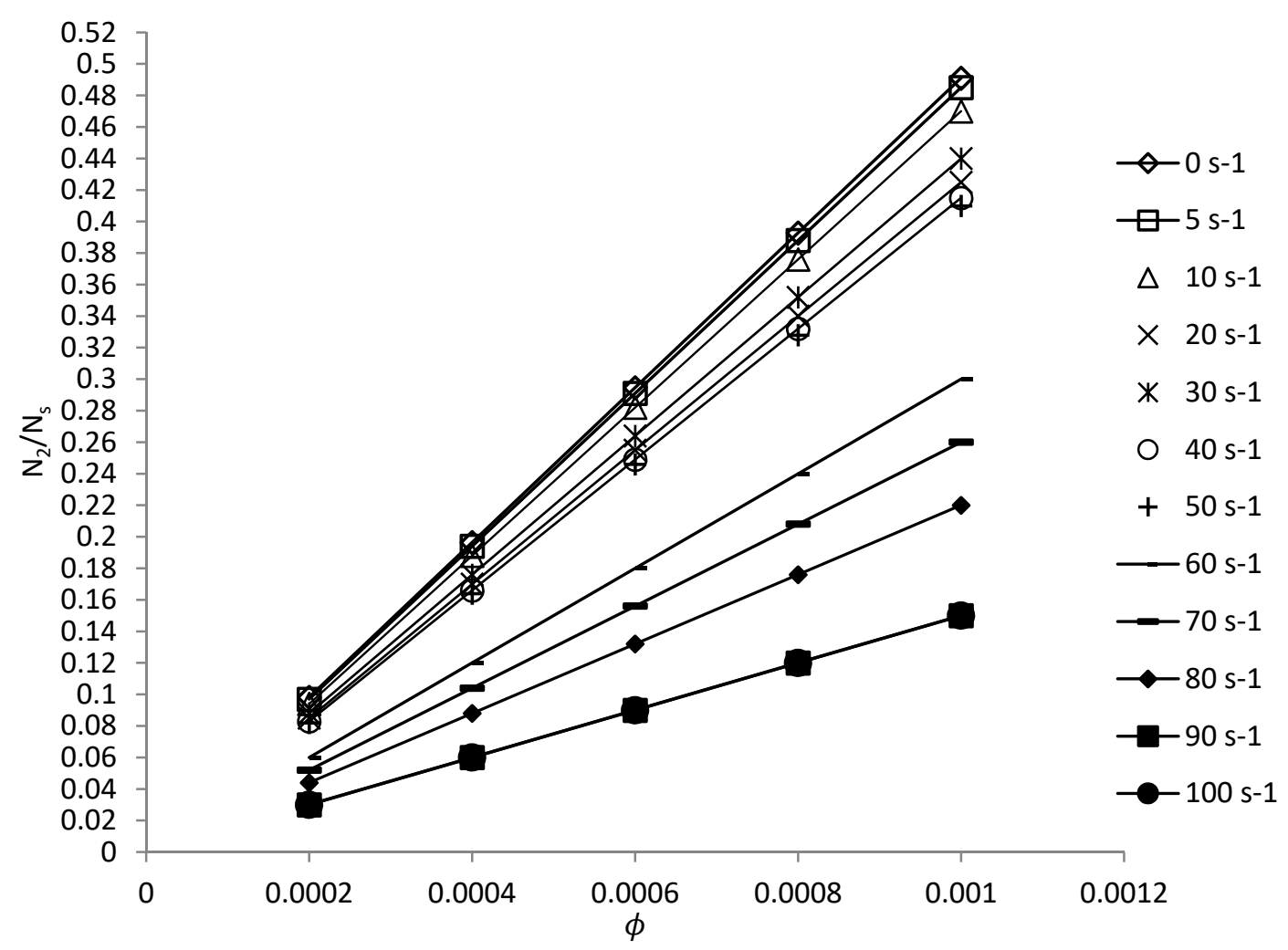

Figure 1. The relationship between the volume fraction $(\phi)$ and $N_{2} / N_{1}$ give straight line go through the origin. Noted decreasing in the line gradient at high shear rate 


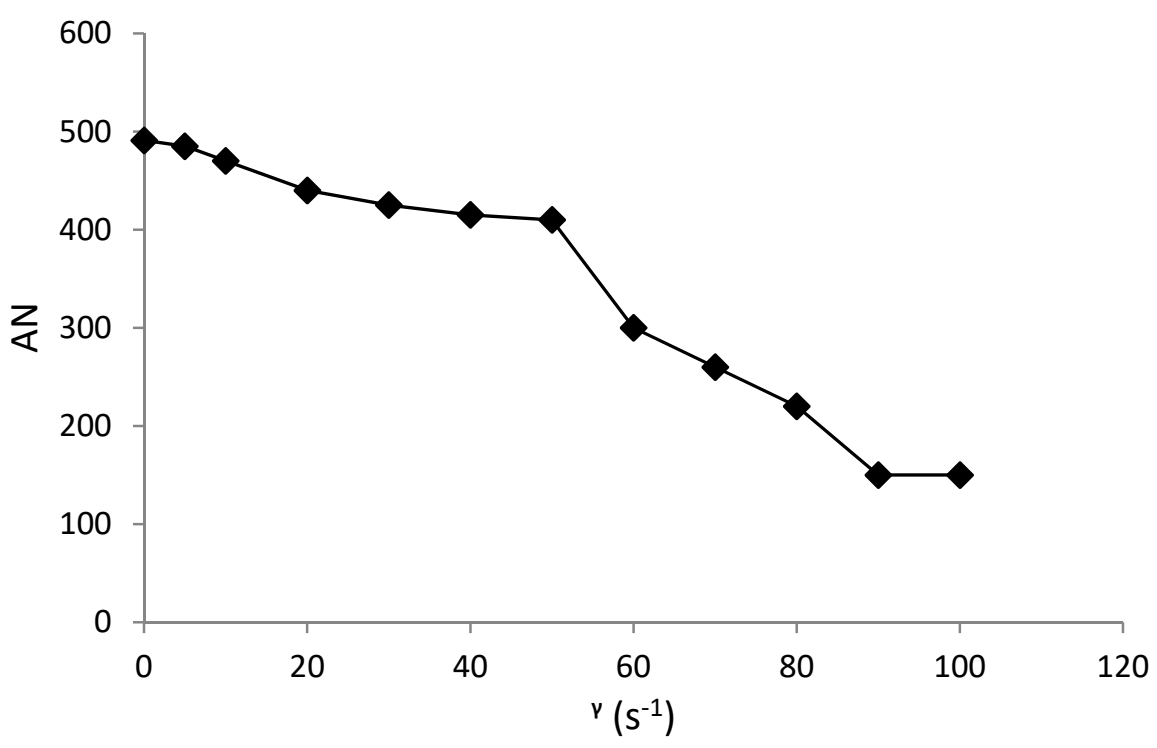

Figure.2 Reducing in EEA at high shear rate. There is a small variation in erythrocytes interaction at very low and very high shear rates

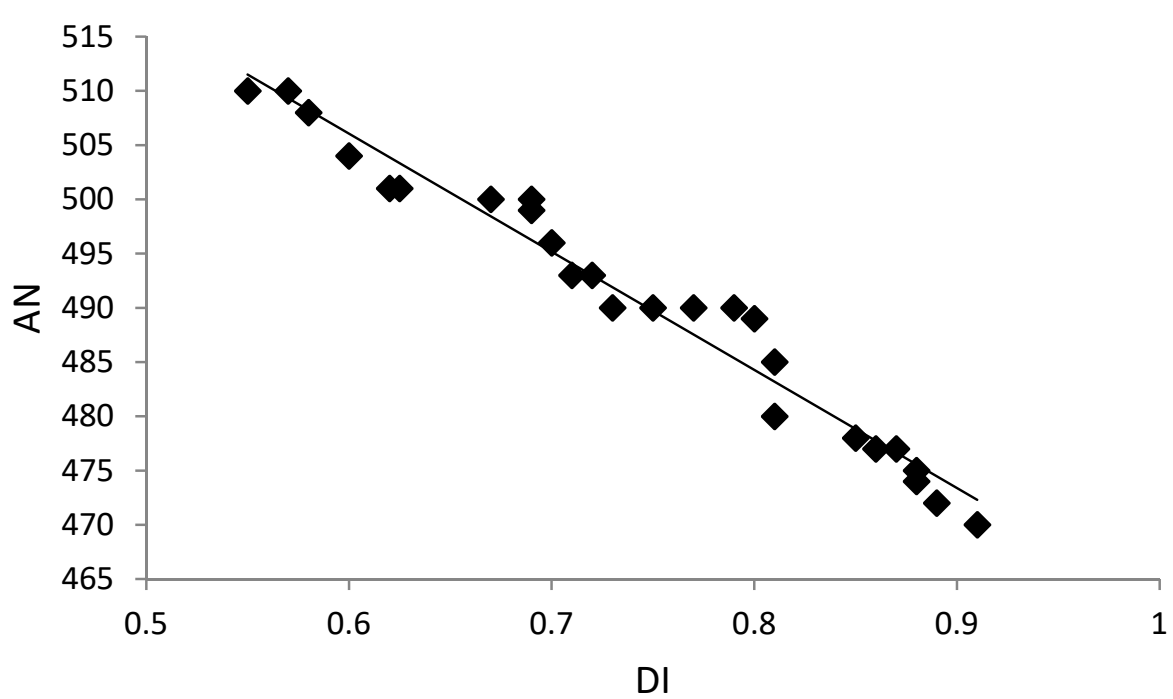

Figure 3. EEA is inversely related to erythrocytes deformation. 


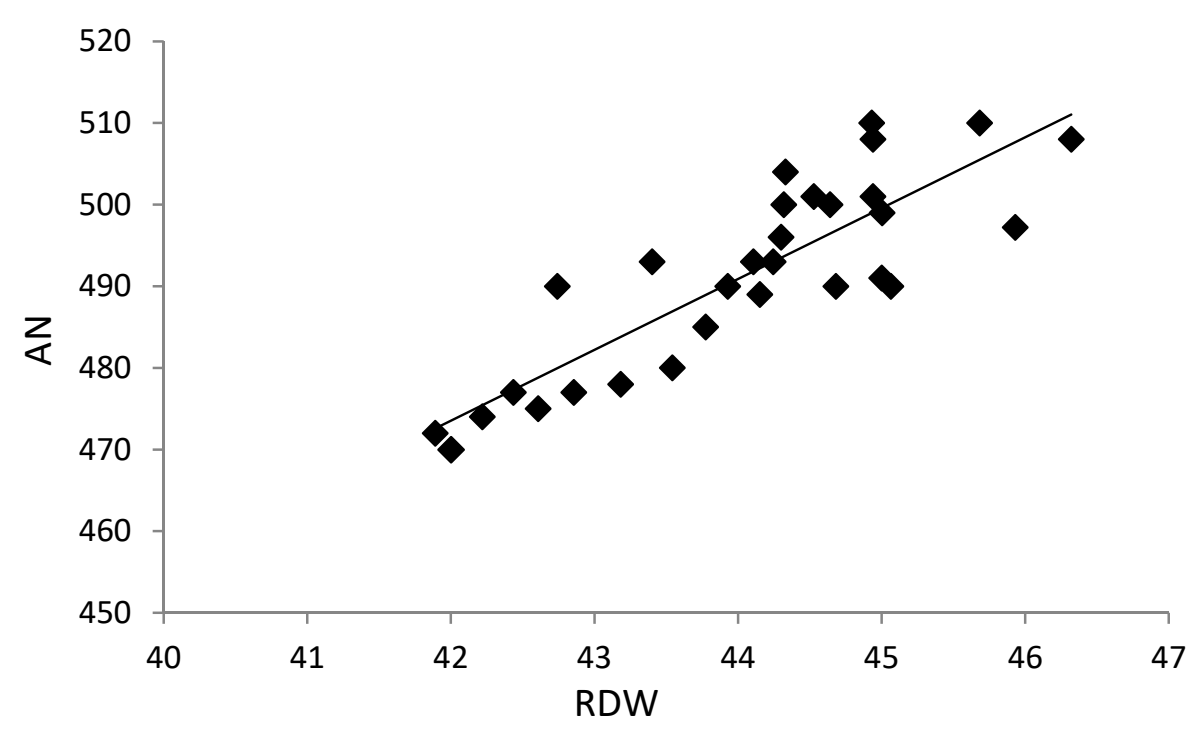

Figure 4. AN and RDW are strongly correlated $\left(\mathrm{R}^{2}=0.7\right)$

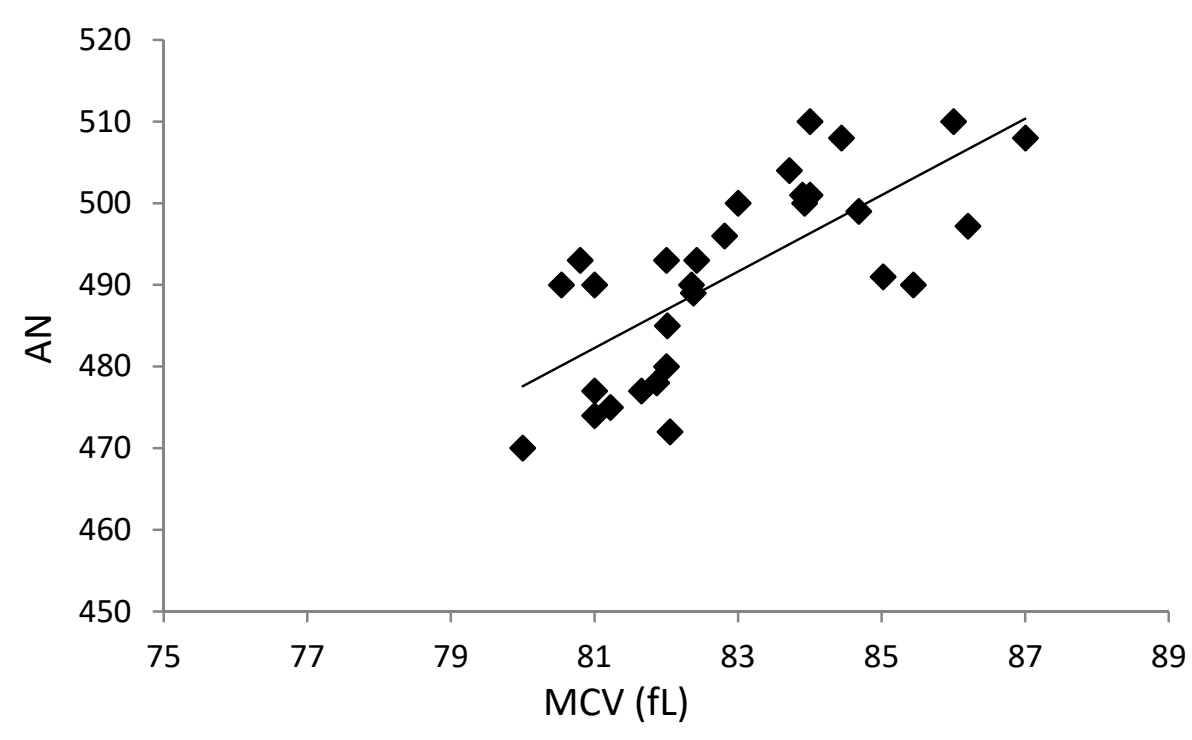

Figure 5. $\mathrm{AN}$ and RDW are moderately correlated $\left(\mathrm{R}^{2}=0.5\right)$

It was assumed that large macromolecules adsorb onto the cell surface and thereby bridge two adjacent cells. This is known by the bridging model of erythrocytes aggregation. These bridging forces must exceed the disaggregation forces such as electrostatic repulsion, to begin the formation of aggregation (Brooks, 1973, 1988; S Chien et al., 1973; Snabre \& Mills, 1985). It has been showed that the intercellular distance is less than the size of the hydrated molecules. Thereby, the cell-cell distance increases with increasing polymer size but is always smaller than the diameter of the hydrated polymer(Asakura \& Oosawa, 1958; Shu Chien \& Jan, 1973). It was depicted that the addition of surface active molecules to the cell suspension effect on erythrocytes adhesion(Attenborough \& Kendall, 2000). Erythrocytes treated with fibronectin exhibited greater adhesion number than normal erythrocytes whereas glutaraldehyde reduced it. Glutaraldehyde reduced the adhesion by about $25 \%$ whereas fibronectin increased the adhesion by $10 \%$ (Kendall \& Stainton, 2001). Ben-Ami, R., et al. suggested a three-way interaction among fibrinogen, Ig, and albumin that synergistically induces erythrocytes aggregation in plasma (Ben-Ami et al., 2003). It was indicated that depletion interaction might play a significant role in erythrocyte adhesion via initiating close contacts and thus suggest the importance of depletion forces for RBC interactions and its relevance to a wide variety of in vitro and in vivo cell-cell and cell-surface interactions (Z. W. Zhang \& Neu, 2009). The 
lifestyle and dietary habits effect on the biochemistry and rheological properties of the blood constitutes including erythrocytes (Ernst et al., 1986). Direct relationship between Fibrinogen concentration in plasma and AN was indicated in the present study with strong correlation $\left(R^{2}=0.7\right)$ Figure 6 . This finding could be explained as fibrinogen plays the major role in the bridging model of erythrocytes aggregation and could be the major factor that causes sticking of erythrocytes with each other. The albumin plays a critical role in maintaining osmotic pressure and fix the shape of erythrocytes. Figure 7 shows increase in AN as albumin concentration increases with moderate correlation $\left(R^{2}=0.5\right)$.

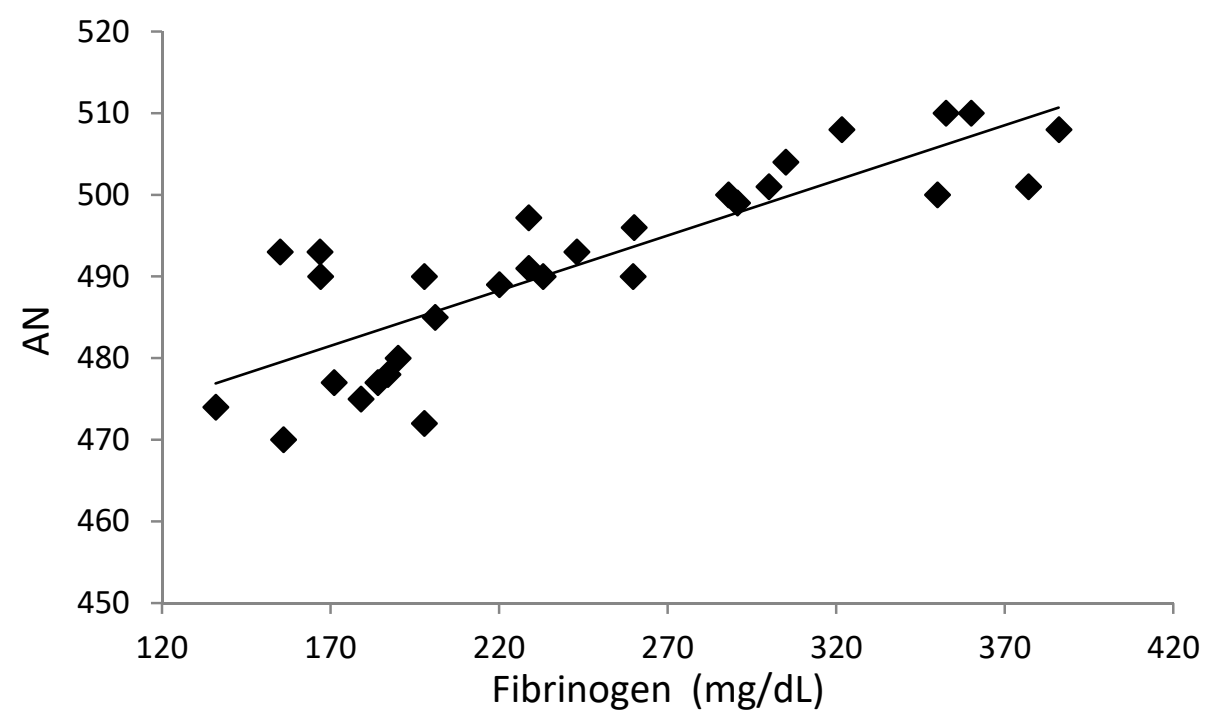

Figure 6. Fibrinogen highly effects on EEA. AN and fibrinogen concentration are strongly and positively correlated $\left(\mathrm{R}^{2}=0.7\right)$

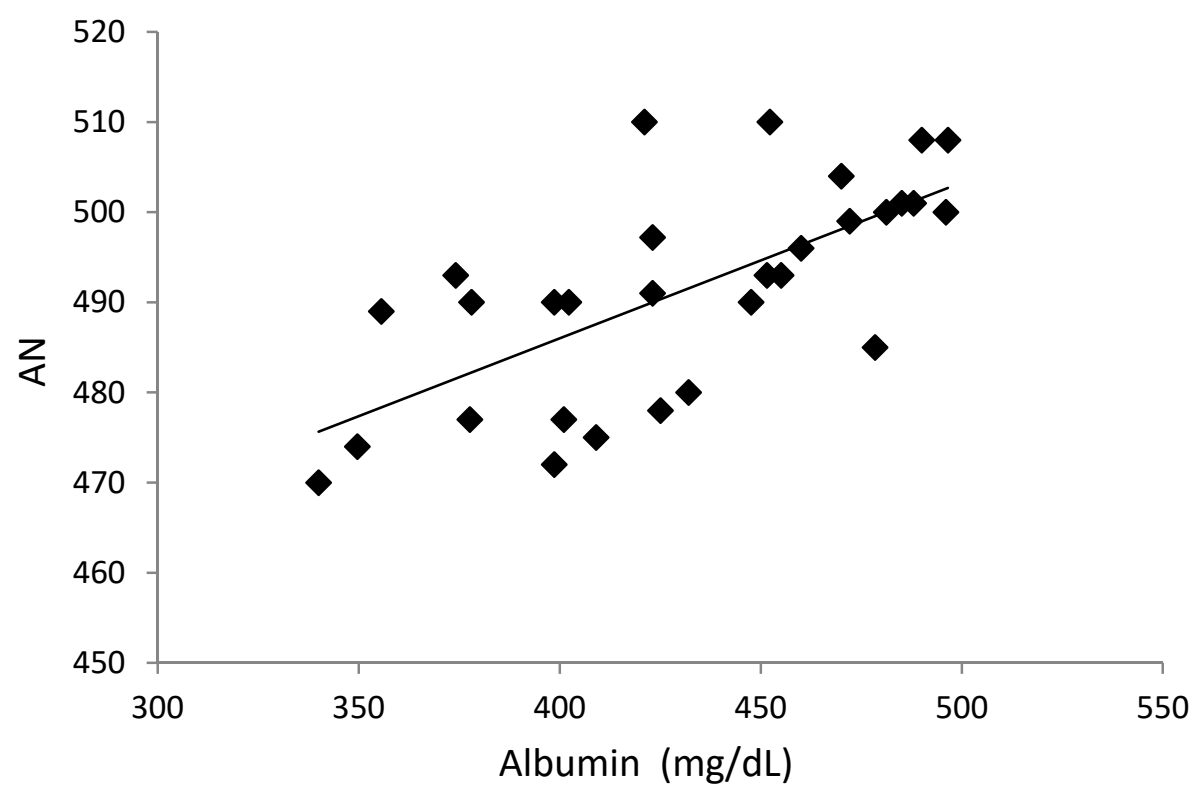

Figure 7. Albumin concentration has a moderate correlation to $\mathrm{AN}\left(\mathrm{R}^{2}=0.5\right)$ 


\section{Conclusion}

Erythrocytes adhesion number can be calculated microscopically in a simple way. Adhesion number reflects the state of the adhesion force of erythrocytes. Adhesion of erythrocytes and adhesion force between erythrocytes could not be considered without taking into account the suspended media composition and the morphology of the erythrocytes themselves.

\section{References}

Asakura, S., \& Oosawa, F. (1958). Interaction between particles suspended in solutions of macromolecules. Journal of Polymer Science, 33(126), 183-192. http://dx.doi.org/10.1002/pol.1958.1203312618

Attenborough, F. R., \& Kendall, K. (2000). Cell—Cell Adhesion of Erythrocytes. The Journal of Adhesion, 74(14), 41-51. http://dx.doi.org/10.1080/00218460008034523

Baskurt, O. K., Meiselman, H., \& Kayar, E. (1998). Measurement of red blood cell aggregation in a "plate-plate" shearing system by analysis of light transmission. Clin Hemorheol Microcirc, 19(4), 307-314.

Ben-Ami, R., Barshtein, G., Mardi, T., Deutch, V., Elkayam, O., Yedgar, S., \& Berliner, S. (2003). A synergistic effect of albumin and fibrinogen on immunoglobulin-induced red blood cell aggregation. Am J Physiol Heart Circ Physiol, 285(6), H2663-H2669.

Berliner, S., Ben-Ami, R., Samocha-Bonet, D., Abu-Abeid, S., Schechner, V., Beigel, Y., . . Barshtein, G. (2004). The degree of red blood cell aggregation on peripheral blood glass slides corresponds to inter-erythrocyte cohesive forces in laminar flow. Thrombosis Research, 114(1), 37-44.

Brittain, J. E., Han, J., Ataga, K. I., Orringer, E. P., \& Parise, L. V. (2004). Mechanism of CD47-induced $\alpha 4 \beta 1$ integrin activation and adhesion in sickle reticulocytes. Journal of Biological Chemistry. http://dx.doi.org/10. 1074/jbc.M407631200

Brooks, D. E. (1973). The effect of neutral polymers on the electrokinetic potential of cells and other charged particles. Journal of Colloid and Interface Science, 43(3), 714-726. http://dx.doi.org/10.1016/00219797(73)90416-5

Brooks, D. E. (1988). Mechanism of Red Cell Aggregation. In D. Platt (Ed.), Blood Cells, Rheology, and Aging (pp. 158-162). Berlin, Heidelberg: Springer Berlin Heidelberg.

Brown, E. J., \& Frazier, W. A. Integrin-associated protein (CD47) and its ligands. Trends in Cell Biology, 11(3), 130-135. http://dx.doi.org/10.1016/S0962-8924(00)01906-1

Chien, S., Dellenback, R., Usami, S., Burton, D., Gustavson, P., \& Magazinovic, V. (1973). Blood volume, hemodynamic, and metabolic changes in hemorrhagic shock in normal and splenectomized dogs. American Journal of Physiology -- Legacy Content, 225(4), 866-879.

Chien, S., \& Jan, K.-m. (1973). Ultrastructural basis of the mechanism of rouleaux formation. Microvascular Research, 5(2), 155-166. http://dx.doi.org/10.1016/0026-2862(73)90068-X

Corn, M. (1961). The adhesion of solid particles to solid surfaces, I. A review. Journal of the Air Pollution Control Association, 11(11), 523-528.

Dahl, K. N., Westhoff, C. M., \& Discher, D. E. (2003). Fractional attachment of CD47 (IAP) to the erythrocyte cytoskeleton and visual colocalization with Rh protein complexes. Blood, 101(3), 1194-1199. http://dx.doi.org/10.1182/blood-2002-04-1187

Dintenfas, L. (1971). of Blood Micro-rheology Viscosity Factors in Blood Flow. Ischemia and Thrombosis (1971 Butterworth Press), Rheology of Blood in Diagnostic and Preventive Medicine,(1976 Butterworth Press), Hyperactivity and Hypertension and Blood Viscosity in Heart Disease and Cancer (1981 Pergamon Press) plus numerous medical papers.

Ernst, E., Pietsch, L., Matrai, A., \& Eisenberg, J. (1986). Blood rheology in vegetarians. Br J Nutr, 56(3), 555560.

Felicetti, M. A., Piantino, F., Coury, J. R., \& Aguiar, M. L. (2008). Influence of removal time and particle size on the particle substrate adhesion force. Brazilian Journal of Chemical Engineering, 25, 71-82.

Garratty, G., Telen, M. J., \& Petz, L. D. (2002). Red cell antigens as functional molecules and obstacles to transfusion. ASH Education Program Book, 2002(1), 445-462. 
Goel, M. S., \& Diamond, S. L. (2002). Adhesion of normal erythrocytes at depressed venous shear rates to activated neutrophils, activated platelets, and fibrin polymerized from plasma. Blood, 100(10), 3797-3803. http://dx.doi.org/10.1182/blood-2002-03-0712

Hermand, P., Gane, P., Huet, M., Jallu, V., Kaplan, C., Sonneborn, H. H., . . Bailly, P. (2003). Red cell ICAM-4 is a novel ligand for platelet-activated $\alpha \mathrm{IIb \beta 3}$ integrin. Journal of Biological Chemistry, 278(7), 4892-4898.

Ihanus, E., Uotila, L. M., Toivanen, A., Varis, M., \& Gahmberg, C. G. (2007). Red-cell ICAM-4 is a ligand for the monocyte/macrophage integrin CD11c/CD18: characterization of the binding sites on ICAM-4. Blood, 109(2), 802-810. http://dx.doi.org/10.1182/blood-2006-04-014878

Janzen, J., Elliott, T. G., Carter, C. J., \& Brooks, D. E. (2000). Detection of red cell aggregation by low shear rate viscometry in whole blood with elevated plasma viscosity. Biorheology, 37(3), 225-237.

Kaliviotis, E., \& Yianneskis, M. (2007). On the effect of dynamic flow conditions on blood microstructure investigated with optical shearing microscopy and rheometry. Proceedings of the Institution of Mechanical Engineers, Part H: Journal of Engineering in Medicine, 221(8), 887-897.

Kendall, K., Liang, W., \& Stainton, C. (1998). New theory and observations of cell adhesion. Proceedings of the Royal Society of London. Series A: Mathematical, Physical and Engineering Sciences, 454(1977), 2529-2533. http://dx.doi.org/10.1098/rspa.1998.0269

Kendall, K., \& Stainton, C. (2001). Adhesion and aggregation of fine particles. Powder Technology, 121(2-3), 223-229. doi: http://dx.doi.org/10.1016/S0032-5910(01)00386-2

Kordecki, M. C., \& Orr Jr, C. (1960). Adhesion of solid particles to solid surfaces. Archives of Environmental Health: An International Journal, 1(1), 1-9.

LaMarche, K. R., Muzzio, F. J., Shinbrot, T., \& Glasser, B. J. (2010). Granular flow and dielectrophoresis: The effect of electrostatic forces on adhesion and flow of dielectric granular materials. Powder Technology, 199(2), 180-188. doi: http://dx.doi.org/10.1016/j.powtec.2010.01.006

Leckband, D., \& Israelachvili, J. (2001). Intermolecular forces in biology. Quarterly reviews of biophysics, 34(02), 105-267.

Liang, W., \& Kendall, K. (1998). Aggregate formation in colloidal dispersions. Colloids and Surfaces A: Physicochemical and Engineering Aspects, 131(1-3), 193-201. doi: http://dx.doi.org/10.1016/S09277757(97)00070-8

Packham, D. E. (2003). Surface energy, surface topography and adhesion. International Journal of Adhesion and Adhesives, 23(6), 437-448. doi: http://dx.doi.org/10.1016/S0143-7496(03)00068-X

Pasini, E. M., Kirkegaard, M., Mortensen, P., Lutz, H. U., Thomas, A. W., \& Mann, M. (2006). In-depth analysis of the membrane and cytosolic proteome of red blood cells. Blood, 108(3), 791-801. doi: 10.1182/blood2005-11-007799

Reid, H., Barnes, A., Lock, P., Dormandy, J., \& Dormandy, T. (1976). A simple method for measuring erythrocyte deformability. Journal of clinical pathology, 29(9), 855-858.

Salazar-Banda, G. R., Felicetti, M. A., Gonçalves, J. A. S., Coury, J. R., \& Aguiar, M. L. (2007). Determination of the adhesion force between particles and a flat surface, using the centrifuge technique. Powder Technology, 173(2), 107-117. doi: http://dx.doi.org/10.1016/j.powtec.2006.12.011

Schmid-Schönbein, H., Gallasch, G., Gosen, J. v., Volger, E., \& Klose, H. (1976). Red cell aggregation in blood flow. Klinische Wochenschrift, 54(4), 159-167.

Shevkoplyas, S. S., Yoshida, T., Gifford, S. C., \& Bitensky, M. W. (2006). Direct measurement of the impact of impaired erythrocyte deformability on microvascular network perfusion in a microfluidic device. Lab on a Chip, 6(7), 914-920.

Shiga, T., Imaizumi, K., Harada, N., \& Sekiya, M. (1983). Kinetics of rouleaux formation using TV image analyzer. I. Human erythrocytes. American Journal of Physiology-Heart and Circulatory Physiology, 245(2), H252$\mathrm{H} 258$.

Shinde Patil, V. R., Campbell, C. J., Yun, Y. H., Slack, S. M., \& Goetz, D. J. (2001). Particle diameter influences adhesion under flow. Biophys $J, 80(4), 1733-1743$.

Shukla, N., \& Henthorn, K. H. (2009). Effect of relative particle size on large particle detachment from a microchannel. Microfluidics and Nanofluidics, 6(4), 521-527. http://dx.doi.org/10.1007/s10404-008-0330-4 
Snabre, P., \& Mills, P. (1985). Effect of dextran polymer on glycocalyx structure and cell electrophoretic mobility. Colloid and Polymer Science, 263(6), 494-500. http://dx.doi.org/10.1007/bf01458340

Telen, M. J. Erythrocyte Adhesion Receptors: Blood Group Antigens and Related Molecules. Transfus Med Rev, 19(1), 32-44. http://dx.doi.org/10.1016/j.tmrv.2004.09.006

Wandersee, N. J., Punzalan, R. C., Rettig, M. P., Kennedy, M. D., Pajewski, N. M., Sabina, R. L., .. . Hillery, C. A. (2005). Erythrocyte adhesion is modified by alterations in cellular tonicity and volume. Br J Haematol, 131(3), 366-377. http://dx.doi.org/10.1111/j.1365-2141.2005.05767.x

Wautier, J. L., \& Wautier, M. P. (2004). Erythrocytes and platelet adhesion to endothelium are mediated by specialized molecules. Clin Hemorheol Microcirc, 30(3, 4), 181-184.

Zafar, U., Hare, C., Hassanpour, A., \& Ghadiri, M. (2014). Drop test: A new method to measure the particle adhesion force. Powder Technology, 264, 236-241. http://dx.doi.org/10.1016/j.powtec.2014.04.022

Zen, Q., Cottman, M., Truskey, G., Fraser, R., \& Telen, M. J. (1999). Critical factors in basal cell adhesion molecule/lutheran-mediated adhesion to laminin. Journal of Biological Chemistry, 274(2), 728-734.

Zhang, D., Kiyatkin, A., Bolin, J. T., \& Low, P. S. (2000). Crystallographic structure and functional interpretation of the cytoplasmic domain of erythrocyte membrane band 3. Blood, 96(9), 2925-2933.

Zhang, Z. W., \& Neu, B. (2009). Role of Macromolecular Depletion in Red Blood Cell Adhesion. Biophys J, 97(4), 1031-1037. doi: http://dx.doi.org/10.1016/j.bpj.2009.06.006

Zhou, S.-A. (2003). On forces in microelectromechanical systems. International Journal of Engineering Science, 41(3-5), 313-335. doi: http://dx.doi.org/10.1016/S0020-7225(02)00207-0

Zimon, A. Adhesion of Dust and Powders; Consultants Bureau: New York, 1982. There is no corresponding record for this reference.

\section{Copyrights}

Copyright for this article is retained by the author(s), with first publication rights granted to the journal.

This is an open-access article distributed under the terms and conditions of the Creative Commons Attribution license (http://creativecommons.org/licenses/by/4.0/). 